\title{
O direito à revisão geral anual dos servidores públicos em tempos de calamidade pública
}

The right to annual general review of public servers in times of public calamity

\section{Renato Nonato Xavier Sobrinho ${ }^{1}$}

\section{RESUMO}

O presente artigo tem como objeto a revisão geral anual dos servidores públicos e investiga a possibilidade de, durante o período de calamidade pública, conter a majoração dos vencimentos, tendo como hipótese a constitucionalidade de tal medida. A pesquisa é eminentemente documental, conduzida com base no método jurídico-dogmático e com uso da revisão de literatura, da legislação e jurisprudência. $\mathrm{O}$ artigo traz a análise de julgados de destaque sobre o tema, bem como discute os dispositivos constitucionais e diplomas legais pertinentes e aborda os aspectos jurídicos da calamidade pública para concluir pela possibilidade de contenção da revisão geral anual durante o período de calamidade pública e pela constitucionalidade da Lei Complementar 173. A pesquisa visa contribuir com o debate acadêmico, haja vista a ainda incipiente produção doutrinária sobre o tema.

Palavras-Chave: Calamidade Pública. Remuneração. Revisão Geral Anual. Servidores Públicos.

\footnotetext{
1 Graduando em Direito pela Universidade Federal da Bahia (UFBA). Membro fundador do Centro Baiano de Estudos Tributários (CET). E-mail: renatosobrinho99@hotmail.com
} 


\section{ABSTRACT}

The purpose of this paper is the annual general review of public servants and investigates the possibility of, during the period of public calamity, containing the increase in salaries, taking as a hypothesis the constitutionality of such measure. The research is eminently documentary, conducted based on the legal-dogmatic method and using literature review, legislation and jurisprudence. The paper provides an analysis of outstanding judgments on the topic, as well as discusses the constitutional provisions and relevant laws and addresses the legal aspects of public calamity to conclude by the possibility of containing the annual general review during the period of public calamity and the constitutionality of the Complementary Law 173. The research aims to contribute to the academic debate, given the still incipient doctrinal production on the subject.

Keywords: Public Calamity. Remuneration. Annual General Review. Public Servants.

Recebido: 08-09-2020

Aprovado: 09-10-2020

\section{INTRODUÇÃO}

Matéria frequentemente associada ao Direito Administrativo, a revisão geral da remuneração dos servidores públicos contempla questões de diversos ramos do Direito, mais especificamente do Direito Financeiro. A discussão de majoração anual de vencimentos naturalmente deságua no debate do orçamento e das finanças públicas de modo geral.

Outrossim, o tema é de grande relevância pela sua atualidade: em 11 de março de 2020, a Organização Mundial de Saúde, tendo em vista a propagação do vírus para mais de 110 países, reconheceu a ocorrência pandemia da Covid-19 (GIRARDI, 2020). O aumento vertiginoso do número de casos da doença levou os Estados a adotarem medidas urgentes 
para a contenção do vírus, as quais, apesar de positivas e imprescindíveis para a proteção da população, naturalmente reverberaram no cenário econômico global e nas finanças públicas de todos os países.

Em observância ao quadro fático supracitado, o Congresso Nacional, em 20 de março do presente ano, aprovou o Decreto Legislativo 6/2020, o qual reconheceu a ocorrência do estado de calamidade pública e ativou uma série de gatilhos previstos na Lei de Responsabilidade Fiscal, a exemplo da dispensa de cumprimento das metas fiscais estabelecidas na Lei de Diretrizes Orçamentárias de 2020 (Lei 13.898/19).

Nesse contexto, diversos movimentos começaram a ser realizados no sentido de disciplinar a conjuntura financeira do Estado brasileiro no período de calamidade e pós-pandemia. Merece destaque aqui a Lei Complementar 173/2020, a qual aborda, dentre outros aspectos, a vedação de majoração de vencimentos dos servidores públicos até 2021 .

Desta forma, resta evidenciado que a revisão geral anual se relaciona diretamente com a calamidade pública, de modo que a discussão acerca da viabilidade jurídica de tal proposta revela-se como uma das questões centrais nesse debate.

À luz do exposto, o presente artigo busca investigar, no primeiro momento, o instituto da revisão, delimitando-o conceitual e historicamente, bem como estudando o posicionamento do Supremo Tribunal Federal nas oportunidades em que o tema fora discutido.

Ademais, almeja-se localizar o objeto no contexto da calamidade pública e verificar a possibilidade de contenção da revisão geral anual. Adotou-se o método hipotético-dedutivo, partindo de premissas gerais para alcançar conclusões específicas. Além disso, foi realizada pesquisa teórica, por meio da consulta e análise dos diplomas normativos nacionais, da doutrina especializada e da jurisprudência pertinente. 


\section{A REVISÃO GERAL ANUAL DOS SERVIDORES PÚBLICOS}

Inicialmente, por razões de recorte metodológico, cumpre realizar a necessária distinção entre a revisão geral anual e o reajuste dos servidores públicos. A doutrina e a jurisprudência ${ }^{2}$ pátrias já se debruçaram sobre esse debate e o pacificaram, contudo, por razões de atecnia legislativa histórica, os termos ainda são confundidos e impactam na regular interpretação do Direito.

O reajuste dos vencimentos é uma majoração real dos valores percebidos pelo servidor público, os quais são alterados em virtude de uma reestruturação do sistema remuneratório vigente, com o fito de valorizar determinada carreira (ELIAS, 2011, p. 4). Tal alteração, pois, decorre de ato discricionário do gestor público que fornece o impulso necessário para iniciar o processo legislativo de reformulação do sistema remuneratório.

Em seu turno, a revisão geral é conceituada como uma majoração nominal da remuneração, a qual objetiva apenas a recuperação do poder de compra de outrora (DI PIETRO, 2019, p. 754). O instituto é aplicado por força do dispositivo constitucional - qual seja, o art. 37, X da Lei Maior - que estabelece a correção anual para evitar que a corrosão da moeda deprecie os valores percebidos pelos servidores. Em síntese, apesar de estarem incluídos no gênero aumento de vencimentos, tais institutos são espécies diferentes de majoração: o reajuste decorre de um juízo político de conveniência, ao passo que a revisão é mandamento constitucional.

Portanto, tendo em vista a inviabilidade de abordagem de duas matérias distintas em um trabalho de tamanho limitado, o presente artigo se restringirá ao estudo da revisão geral anual.

\footnotetext{
2 É ver, nesse sentido, a título de reforço para melhor compreensão, os didáticos votos dos Ministros Carlos Britto e Cármen Lúcia no julgamento da ADI 3599-1/DF.
} 


\subsection{A REVISÃO ANTES DA EMENDA CONSTITUCIONAL $19 / 1998$}

Promulgada em 5 de outubro de 1988, a Constituição da República Federativa do Brasil - $\mathrm{CF} / 88$ remodelou o ordenamento jurídico pátrio ao concretizar um amplo leque de direitos e garantias fundamentais, irradiando-os ao longo do diploma normativo.

A nova ordem constitucional trouxe importantes inovações, dentre as quais se destaca a inclusão, no Capítulo VII - Da Administração Pública, de uma nova garantia para os quadros do funcionalismo, qual seja, a revisão periódica dos vencimentos, in verbis:

Art. 37. A administração pública direta, indireta ou fundacional, de qualquer dos Poderes da União, dos Estados, do Distrito Federal e dos Municípios obedecerá aos princípios de legalidade, impessoalidade, moralidade, publicidade e, também, ao seguinte:

$[\ldots]$

X - a revisão geral da remuneração dos servidores públicos, sem distinção de índices entre servidores públicos civis e militares, far-se-á sempre na mesma data;

Para uma análise mais apurada deste dispositivo faz-se imperioso compreendê-lo sob uma perspectiva histórica.

O Brasil foi, durante as décadas de 80 e 90, assolado pelo fenômeno da hiperinflação, o qual é definido pela literatura econômica quando os índices superam a faixa dos $50 \%$ ao mês. O processo hiperinflacionário é ainda concebido como um desarticulador da economia pelo seu impacto devastador no sistema de preços de um país (CORAZZA, 1990, p. 213).

A título de registro, os dados da época apontam que a inflação acumulada em 1988 foi de 933,62\%, ao passo que em 1989 alcançou a marca de $1.764,86 \%$ (CORAZZA, 1990, p. 214). Seis planos econômicos tentaram conter o avanço da hiperinflação, todos eles sem sucesso perene, até 
que sobreveio a Medida Provisória n ${ }^{\circ}$ 542, de 30 de junho de 1994, que instituiu o Plano Real e pôs fim a 15 anos de descontrole monetário.

Antes disso, no entanto, merece destaque o Decreto-Lei 2335, de 12 de junho de 1987, o qual ficou popularmente conhecido como Plano Bresser. Tal diploma normativo marca a positivação da política de congelamento de preços no país, mas também traz importantes disposições sobre o "reajuste" 3 dos vencimentos dos servidores ao assegurar a majoração mensal dos valores percebidos ${ }^{4}$. A atenção do Poder Executivo - no exercício da função atípica de legislar conferida pela Carta de 1967 - está voltada, por evidente, à proteção da remuneração do funcionalismo em face da corrosão da moeda.

É nesse contexto de escalada vertiginosa da inflação e desvalorização diária da moeda - e, por conseguinte, dos vencimentos - que se insere o constituinte originário. A questão do impacto inflacionário na remuneração do trabalhador estatutário esteve presente nos debates da Assembleia Constituinte $^{5}$, órgão este que não poderia se fechar à realidade à sua volta.

Naturalmente, a Constituição Cidadã, no ímpeto de consolidar um Estado de Bem Estar Social, positivou a periodicidade das revisões como forma de proteger a remuneração dos servidores da corrosão hiperinflacionária (MARIANO, 2002, p. 152). Em nosso sentir, o passado do Poder Executivo em matéria de reajuste remuneratório - tais como reajustes irrisórios e sem regularidade temporal - também colaborou para que o constituinte instituísse um mecanismo para compelir o gestor a proteger o poder de compra dos servidores.

\footnotetext{
3 Apesar da ressalva feita no tópico anterior acerca do uso da terminologia, neste caso o termo reajuste é adequado, uma vez que a expressão revisão só veio a ser adotada posteriormente, com a promulgação da Constituição de 1988.

4 Art. $8^{\circ}$ Fica assegurado aos trabalhadores, a título de antecipação, o reajuste mensal dos salários, inclusive do salário mínimo, pensões, proventos e remuneração em geral, em proporção idêntica à variação da Unidade de Referência de Preços (URP), excetuado o mês da data-base.

$\S 1^{\circ}$ É extensivo aos servidores civis e militares da União e de suas autarquias, o reajuste de que trata este artigo. 5 É ver, nesse sentido, as atas das reuniões da Subcomissão dos Direitos dos Trabalhadores e Servidores Públicos da Assembleia Constituinte, nas quais discutiu-se a forma de inclusão do instituto no projeto (BRASIL, 1987).
} 
Pouco mais de dois meses após a promulgação da Constituição, foi editada a Lei 7.706, a qual fixou o mês de janeiro como data-base para as revisões ${ }^{6}$ dos vencimentos ${ }^{7}$. No entanto, apesar de tal delimitação legal, não havia obrigatoriedade de revisão anual. É que a redação originária do inciso $\mathrm{X}$ do art. 37 apenas se referia à necessidade de uma data fixa, sem, no entanto, determinar uma periodicidade. A norma constitucional, ademais, garantia a revisão tanto para os servidores civis quanto militares.

O Supremo Tribunal Federal, quando instado a se manifestar sobre o tema no Mandado de Segurança - MS 22.439/DF, reconheceu a ausência de uma periodicidade delimitada, rígida. Apesar disso, ao longo dos anos, novos diplomas foram editados prevendo revisões sempre no dia $1^{\circ}$ de janeiro do ano seguinte, em consonância com o disposto na Lei 7.706/88 (MARIANO, 2002, p. 152-153).

Impende repisar que a redação original não previa a revisão anual da remuneração dos quadros da Administração Pública. Tal periodicidade foi ditada de forma infraconstitucional pelas leis ordinárias promulgadas no período como forma de assegurar a preservação do poder de compra dos servidores em um período no qual a inflação rapidamente corroía o valor real da moeda.

\subsection{A REVISÃO APÓS A EMENDA CONSTITUCIONAL 19/1998 E A JURISPRUDÊNCIA DO SUPREMO TRIBUNAL FEDERAL}

Posteriormente, com o advento da Emenda Constitucional 19 de 1998, a periodicidade foi incluída no texto, delimitando o instituto para a versão atual, qual seja, a revisão geral anual:

\footnotetext{
$6 \quad$ Faz-se imperioso observar que o legislador se atentou para a adaptação da linguagem, agora alinhada ao dispositivo constitucional mencionado.

$7 \quad$ Art. $1^{\circ}$ A partir de 1989, o mês de janeiro será considerado data-base das revisões dos vencimentos, salários, soldos e proventos dos servidores, civis e militares, da Administração Federal direta, das autarquias, dos extintos Territórios Federais e das fundações públicas.
} 


\begin{abstract}
$\mathrm{X}$ - A remuneração dos servidores públicos e o subsídio de que trata o $\S 4^{\circ}$ do art. 39 somente poderão ser fixados ou alterados por lei específica, observada a iniciativa privativa em cada caso, assegurada revisão geral anual, sempre na mesma data e sem distinção de índices;
\end{abstract}

A nova redação é vista pela doutrina como uma conquista de direito pelo funcionalismo público (SILVA, 2008), na medida em que garantiu a regra da anualidade para repor as perdas decorrentes da corrosão inflacionária. Por outro lado, impôs uma severa restrição à discricionariedade do gestor público, uma vez que limitou sua margem de decisão ao período de um ano.

No entanto, decorridos mais de 12 meses desde a promulgação da emenda, os chefes do Poder Executivo de diversos entes da federação não enviaram ao respectivo Poder Legislativo o projeto de lei para revisão dos vencimentos. Tal abstenção desencadeou movimentos de diversas categorias do funcionalismo e desaguou em uma série de Ações Diretas de Inconstitucionalidade - ADI sobre o tema ${ }^{8}$.

Na ADI 2061/DF, de relatoria do então Ministro Ilmar Galvão, fora julgado procedente o pedido de reconhecimento da mora do Poder Executivo de enviar o projeto de revisão geral dos vencimentos dos servidores públicos da União. O voto condutor do relator sustentava a tese de que a nova redação do inciso X do art. 37, ao instituir a periodicidade anual, vincula o chefe do Poder Executivo à proposição da revisão a cada exercício, de modo a repor as perdas inflacionárias de cada período.

No entanto, ainda se perpetua a divergência na doutrina e na jurisprudência - em especial das Cortes de Contas do país - acerca da iniciativa de proposição da revisão.

A primeira corrente aduz que os Poderes e órgãos satélites, por força da separação de Poderes e da independência financeira, possuem autonomia para impulsionar o processo legislativo de revisão remuneratória (COELHO, 2012, p. 234-235).

$8 \quad$ Vide ADI n ${ }^{\circ}$ 2.061-DF, referente à omissão do Presidente da República, e as ADIs nº 2.481-RS, 2.486RJ, 2.490-PE, 2.492-SP e 2.525-DF, quanto aos Governadores de estados e do Distrito Federal. 
A segunda corrente, por outro lado, prega que a competência é do presidente da República (BANDEIRA DE MELLO, 2015, p. 285-286) por força do art. $61, \S 1^{\circ}$, II, a ${ }^{9}$ da Lei Maior, estendido aos chefes do Poder Executivo dos demais entes federados pelo princípio da simetria. Ademais, por se tratar de revisão geral, se irradia de modo uniforme para todos os quadros do funcionalismo público do ente (FERRAZ, 2013, p. 859).

Em nosso sentir, a última linha se mostra mais adequada, pois reconhece a posição do gestor público enquanto responsável pela alocação preliminar dos recursos, por meio do regular procedimento de natureza não apenas administrativa, mas também política, de elaboração da proposta de orçamento.

A redação do dispositivo constitucional corrobora tal entendimento ao vedar a distinção de índices, na medida em que o processo legislativo fracionado, bem como eventual omissão de um dos chefes dos Poderes, pode ocasionar uma disparidade de índices, de modo que a iniciativa privativa do Chefe do Executivo é imperativo para assegurar a revisão isonômica. Nesse sentido, a tese de propostas segmentadas se adéqua às propostas de reajuste remuneratório, na qual a Lei Maior já preconiza a observância à iniciativa dos chefes dos demais Poderes.

Arguir que cada Órgão pode, individualmente, propor o projeto é chancelar a desarmonia entre os poderes, numa relação em que cada um delibera sobre a sua revisão, sem a necessária observância aos demais e, principalmente, ao vínculo que os une enquanto ente.

O posicionado firmado na ADI 2061 manteve-se sedimentado ao

9 Art. 61. A iniciativa das leis complementares e ordinárias cabe a qualquer membro ou Comissão da Câmara dos Deputados, do Senado Federal ou do Congresso Nacional, ao Presidente da República, ao Supremo Tribunal Federal, aos Tribunais Superiores, ao Procurador-Geral da República e aos cidadãos, na forma e nos casos previstos nesta Constituição.

$\S 1^{\circ}$ São de iniciativa privativa do Presidente da República as leis que:

$[\ldots]$

II - disponham sobre:

a) criação de cargos, funções ou empregos públicos na administração direta e autárquica ou aumento de sua remuneração; $[\ldots]$ 
longo dos anos, até que, em abril de 2014, durante o julgamento do RE 565.089/SP, o Ministro Roberto Barroso inaugurou a divergência ao pugnar pela aplicação de um novo sentido ao termo revisão, distinto do até então utilizado. $\mathrm{O}$ julgador argumentou no sentido de compreender que a norma demanda uma avaliação anual dos vencimentos, a partir da qual definir-se-á se o aumento será ou não concedido ${ }^{10}$.

Ademais, faz-se mister discutir a vedação de vinculação de remuneração, preconizada no inciso XIII do art. 37 da Constituição Federal ${ }^{11}$.

Respeitável é a parcela da doutrina que milita pela tese da revisão geral anual automática. José Afonso da Silva preleciona que o texto constitucional garante a alteração do valor das remunerações como consequência da correção monetária. Aponta ainda que a majoração só pode ser feita para aumentar as remunerações, em virtude da garantia da irredutibilidade dos vencimentos. Nesse sentido, a revisão compreenderia um aumento anual vinculado ao processo inflacionário (SILVA, 2008, p. 340).

Impende assinalar que o Poder Judiciário vem atuando para conter apenas os atos que impliquem em redução direta dos vencimentos ${ }^{12} \mathrm{em}$ observância a norma do inciso XV do art. 37. Contudo, a jurisprudência já está sedimentada no sentido de permitir a redução indireta, haja vista que os vencimentos não acompanham automaticamente os índices inflacionários (CARVALHO FILHO, 2015, p. 779).

Tal impossibilidade decorre do inciso XIII do art. 37 da Carta Cidadã, o qual veda qualquer vinculação das espécies remuneratórias para o efeito de remuneração de pessoal. A opção se mostra positiva no ponto de

$10 \quad$ Recomenda-se a leitura integral do voto do Ministro Roberto Barroso no acórdão mencionado.

11 Art. 37. A administração pública direta e indireta de qualquer dos Poderes da União, dos Estados, do Distrito Federal e dos Municípios obedecerá aos princípios de legalidade, impessoalidade, moralidade, publicidade e eficiência e, também, ao seguinte:

$[\ldots]$

XIII - é vedada a vinculação ou equiparação de quaisquer espécies remuneratórias para o efeito de remuneração de pessoal do serviço público;

12 O Supremo Tribunal Federal, no julgamento da ADI 2238, declarou a inconstitucionalidade do $\S 2^{\circ}$ do art. 23 da LRF, o qual previa a possibilidade de redução de vencimentos e carga horária dos servidores públicos. A eficácia do dispositivo estava suspensa em virtude de medida cautelar concedida anteriormente. 
vista financeiro, na medida em que assegura aos Poderes Executivo e Legislativo o controle do orçamento público, evitando que os gastos estatais entrem em uma trajetória de crescimento descontrolada.

A Suprema Corte brasileira também comunga deste entendimento: um dos argumentos utilizados no RE 565.089 para rejeitar a tese da revisão automática foi a impossibilidade de vincular a remuneração dos servidores federais aos índices inflacionários. O referido tribunal já havia decidido nessa forma anteriormente em julgado referente aos entes subnacionais. Esse precedente serviu de paradigma para edição da Súmula Vinculante $42^{13}$. O Recurso Extraordinário ora em comento teve a repercussão geral reconhecida e, com a conclusão do julgamento em 2019, a tese divergente foi transformada no Tema 19, in verbis:

O não encaminhamento de projeto de lei de revisão anual dos vencimentos dos servidores públicos, previsto no inciso $\mathrm{X}$ do art. 37 da CF/1988, não gera direito subjetivo a indenização. Deve o Poder Executivo, no entanto, se pronunciar, de forma fundamentada, acerca das razões pelas quais não propôs a revisão.

O novo posicionamento se mostra mais compatível com a realidade, na medida em que o gestor público continua vinculado ao art. 37, X da Constituição e deverá emitir um posicionamento sobre o tema, sem, no entanto, impor uma revisão automática, à revelia da realidade fiscal do ente.

Em outro julgado de relevância, o Recurso Extraordinário 905.357/ RR, de relatoria do Ministro Alexandre de Moraes, a Suprema Corte brasileira decidiu pela impossibilidade de concessão da revisão geral anual quando tal majoração de vencimentos está prevista apenas na Lei de Diretrizes Orçamentárias. A matéria teve a repercussão geral reconhecida sob o Tema 684, sendo fixada a seguinte tese: "A revisão geral anual da remuneração dos servidores públicos depende, cumulativamente, de dotação na Lei Orçamentária Anual e de previsão na Lei de Diretrizes Orçamentárias”.

13 É inconstitucional a vinculação do reajuste de vencimentos de servidores estaduais ou municipais a indices federais de correção monetária. 
A decisão teve como fundamento a norma insculpida no art. 169, $\S 1^{\circ}$ e incisos, os quais preconizam os requisitos para aumento de remuneração dos servidores públicos: (i) prévia dotação orçamentária para suportar a majoração de despesa e seus acréscimos; e (ii) a autorização na Lei de Diretrizes Orçamentárias ${ }^{14}$.

Em nosso sentir, a decisão se mostrou adequada, haja vista que os requisitos - já presentes no texto originário - vinculam toda a Administração Pública à regra de prudência fiscal, de modo a vedar os aumentos de despesa que não estejam previstos nos diplomas orçamentários. O dispositivo, por conseguinte, reforça a posição do orçamento enquanto norteador do planejamento e execução das atividades do Poder Público (ABRAHAM, 2018, p. 314).

Não pode, portanto, um Poder ou Órgão Constitucional demandar a revisão geral sem que haja previsão na LDO e na LOA, uma vez que tais normas são dotadas de suficiente rigidez para inviabilizar quaisquer tentativas de descumprimento (LEITE, 2011, p. 70). O aumento de despesas deve se submeter ao crivo do Poder Legislativo, sob pena de restar configurada afronta legal e constitucional.

Desta forma, resta evidenciado que a revisão geral anual não se aplica de forma automática, devendo (i) o percentual ser previsto em lei específica; (ii) ser autorizada pela Lei de Diretrizes Orçamentárias; e (iii) possuir dotação orçamentária na LOA para atender o novo gasto.

\footnotetext{
14 Art. 169. A despesa com pessoal ativo e inativo da União, dos Estados, do Distrito Federal e dos Municípios não poderá exceder os limites estabelecidos em lei complementar.

$\S 1^{\circ}$ A concessão de qualquer vantagem ou aumento de remuneração, a criação de cargos, empregos e funções ou alteração de estrutura de carreiras, bem como a admissão ou contratação de pessoal, a qualquer título, pelos órgãos e entidades da administração direta ou indireta, inclusive fundações instituídas e mantidas pelo poder público, só poderão ser feitas:

I - se houver prévia dotação orçamentária suficiente para atender às projeções de despesa de pessoal e aos acréscimos dela decorrentes;

II - se houver autorização específica na lei de diretrizes orçamentárias, ressalvadas as empresas públicas e as sociedades de economia mista.
} 


\section{A (IM)POSSIBILIDADE DE CONTENÇÃO DA REVISÃO GE- RAL ANUAL NO CONTEXTO DE CALAMIDADE PÚBLICA}

O sistema constitucional das crises é definido pela doutrina como um conjunto de instrumentos rigorosos de controle de direitos fundamentais, os quais só podem ser aplicados em hipóteses de evidente excepcionalidade. No Brasil, a Constituição Federal de 1988 dispõe sobre duas espécies: o estado de defesa e o estado de sítio (CRUZ, 2020, p. 108).

Humberto Alves de Campos (2011, p. 84) preleciona que:

A decretação da emergência constitucional não implica suspensão da Constituição nem importa situação de extraconstitucionalidade, mas ocorre a substituição de legalidade comum pela legalidade extraordinária, delineada no sistema constitucional das crises. O sistema constitucional das crises, portanto, autoriza a instituição de medidas de exceção no Estado de Direito, mas não a instituição de um estado de exceção.

Não há uma definição precisa na literatura acerca dos princípios norteadores do sistema de crise (CAMPOS, 2011, p. 109), logo, por este não ser o objeto do presente trabalho, nos filiamos às lições de Aricê Moacyr Amaral Santos (1981, p. 33, apud ARAÚJO; NUNES JÚNIOR, 2001, p. 276) para adotar os princípios da necessidade (existência dos requisitos fáticos justificadores); temporariedade (marcos temporais devidamente delimitados); e proporcionalidade (as medidas e instrumentos aplicados são proporcionais aos fatos que as justificaram).

Por outro lado, a calamidade pública não possui um regramento específico na Lei Maior, tendo sido contemplada apenas em alguns dispositivos esparsos ao longo do texto constitucional: (i) a competência da União para planejar e promover a defesa permanente (art. 21, XVIII); (ii) a ocupação e uso temporário de bens e serviços públicos (art. 136, § $1^{\circ}$, II); (iii) instituição de empréstimo compulsório (art. 148, I); e (iv) abertura de crédito extraordinário (art. $167, \S 3^{\circ}$ ). 
Nesse sentido, em matéria financeira e fiscal, a Lei de Responsabilidade Fiscal - LRF preconizou, em seu art. 65, uma série de suspensões e flexibilizações de dispositivos do seu próprio texto, com o fito de nortear a atuação dos entes durante os períodos de excepcionalidade e preencher a lacuna normativa. Ao estabelecer o reconhecimento do Poder Legislativo como condição para decretação da calamidade pública, a LRF afasta a possibilidade de juízos subjetivos de oportunidade ativarem os mecanismos legais excepcionais.

Ademais, pela ausência de regulamentação constitucional, a literatura contemporânea não busca se aprofundar no estudo da matéria. Contudo, é possível encontrar maior suporte doutrinário no século XX: Hésio Fernandes Pinheiro concebia a calamidade pública como um "mal notório", o qual afeta profundamente a sociedade e desencadeia situações de excepcionalidade (PINHEIRO, 1954, p. 44).

É possível inferir, portanto, que o estado de calamidade pública é um estado de crise. Essa, por seu turno, pode ser entendida como uma situação de profunda anormalidade e instabilidade, a qual se torna insustentável ao ponto de conduzir o Estado à adoção de instrumentos de proteção excepcionais (PASCOETTO, 2012, p. 180).

Nesse contexto, surge o questionamento acerca dos limites da regulamentação da calamidade pública, haja vista que, apesar da omissão constitucional, o regramento instituído - ou a ser instituído - deve observar algum parâmetro.

Em nosso sentir, o silêncio da Lei Maior não desvincula o legislador nem o intérprete da observância dos ditames constitucionais. Contudo, a situação de excepcionalidade que se impõe demanda um tratamento específico, o qual entendemos que deve ser norteado pelos mesmos princípios que conduzem o sistema constitucional de crises. É dizer, a normatização da calamidade pública deverá estar em consonância com os princípios da necessidade, temporariedade e proporcionalidade, sob pena de configurar injusta restrição de direitos. 
No que se refere à necessidade, a concretização fática da calamidade é o requisito primordial para a instauração de medidas excepcionais, de modo que suposições infundadas não devem ser aceitas como justificativa. A análise apurada e prudente dos fatos impede que o quadro excepcional seja instituído por força dos fluxos políticos.

A temporariedade, por seu turno, é o limite objetivo do estado de excepcionalidade. A delimitação temporal deve ser rígida e adequada à situação fática, de modo que a contenção do direito não pode se perpetuar; deve, por outro lado, ser ajustada de acordo com a calamidade.

Por fim, a proporcionalidade deriva da técnica de ponderação e se assemelha ao conceito de proporcionalidade em sentido estrito (ALEXY, 2008). Este requisito preconiza um equilíbrio de forças e o estudo das repercussões e externalidades derivadas do mecanismo selecionado, de modo a compatibilizar o meio com os fins almejados. Humberto Ávila (2005, p. 116) preleciona que a verificação da proporcionalidade demanda o exame das vantagens ligadas à promoção do fim e se estas justificam as desvantagens decorrentes do meio empregado.

Sobre o sistema constitucional de crises, Gabriel Dias Marques da Cruz (2020, p. 109) pontua ainda que a legalidade deve permanecer preservada para delimitar a atuação do Estado, mas a contenção e/ou a supressão temporária dos direitos fundamentais são medidas que podem ser adotadas para proteger o interesse público.

Nesse sentido, entendemos que não cabe ao Poder Executivo, por mero juízo de conveniência, instituir medidas de excepcionalidade, mas sim ao Poder Legislativo; o dever de limitação pertence ao legislador e é a Lei que deve regular as medidas a serem adotadas. 


\section{A VEDAÇÃO DE CONCESSÃO DA REVISÃO GERAL ANU- AL NA LEI COMPLEMENTAR 173/2020}

Em 27 de maio de 2020 foi promulgada a Lei Complementar 173, a qual instituiu o Programa Federativo de Enfrentamento ao Coronavírus. O novo diploma legal prevê, em seu art. $8^{\circ}$, dentre outras medidas, a vedação de majoração dos vencimentos dos quadros do funcionalismo de todos os planos da Federação:

Art. $8^{\circ} \mathrm{Na}$ hipótese de que trata o art. 65 da Lei Complementar $\mathrm{n}^{\mathrm{o}} 101$, de 4 de maio de 2000, a União, os Estados, o Distrito Federal e os Municípios afetados pela calamidade pública decorrente da pandemia da Covid-19 ficam proibidos, até 31 de dezembro de 2021, de:

I - conceder, a qualquer título, vantagem, aumento, reajuste ou adequação de remuneração a membros de Poder ou de órgão, servidores e empregados públicos e militares, exceto quando derivado de sentença judicial transitada em julgado ou de determinação legal anterior à calamidade pública; ${ }^{15}$

Tal alteração suscitou questionamentos acerca da sua constitucionalidade, os quais culminaram no ajuizamento de três Ações Diretas de Inconstitucionalidade ${ }^{16}$. Dentre os argumentos apresentados, assinalou-se que a referida lei viola a separação dos Poderes e a autonomia dos entes federados.

De início, cumpre diferenciar dois institutos legislativos: a Lei Nacional e a Lei Federal. Apesar de ambas serem editadas pelo Congresso Nacional, a primeira dispõe de normas a serem observadas pelos entes federados dos três níveis, ao passo que a segunda traz regulamentação apenas para a União (BENEDET, 2006, p. 308).

No caso em tela, a Lei Complementar 173 se enquadra na definição de lei nacional, uma vez que o programa federativo instituído vincula a atuação da União, dos Estados e dos Municípios no combate ao coronavírus, estabelecendo direitos e contrapartidas para cada um destes.

15 Como visto no tópico 2 deste artigo, os termos revisão e reajuste possuem, na perspectiva doutrinária, significados distintos. No entanto, no caso ora sob análise, resta evidenciado que o legislador complementar optou por tratar os institutos como sinônimos, instituindo uma vedação para toda e qualquer majoração de vencimentos. 16 É ver, nesse sentido, as ADIs 6444, 6447 e 6450, todas sob relatoria do Min. Alexandre de Moraes. 
Inexiste, por conseguinte, mácula à separação dos Poderes ou à autonomia federativa; pelo contrário, reforça a harmonia das instituições e o Pacto Federativo, na medida em que congrega todo o Estado brasileiro no esforço de contenção do crescimento do gasto com pessoal em um momento de fragilidade fiscal. Não se pode, pois, chancelar a possibilidade de um Poder, Órgão ou Ente se desvincular da regra do art. $8^{\circ}$, sob pena de se provocar um desequilíbrio interno no Ente ou a sobreposição de um dos planos federados.

O modelo federativo pressupõe a atuação do ente central enquanto condutor das políticas estabilizadoras, delineando o arquétipo normativo de responsabilidade com relação aos gastos, de modo a estabilizar as despesas e evitar oscilações (ANDRADE, 2012, p. 57).

Por se tratar de revisão geral, o movimento de um Poder, se bem sucedido, estende seus benefícios para todo o quadro da Administração Pública, contudo, prejudica diretamente o Poder Executivo e indiretamente a sociedade, haja vista que, em um momento de redução de receitas, as despesas obrigatórias (nesse caso os gastos com pessoal) se avolumam, comprometendo uma parcela ainda maior do orçamento. Esse engessamento é nocivo, pois reduz a margem de discricionariedade do gestor público em um momento de fragilidade sanitária, social e fiscal, no qual existe incontestável necessidade de alocação dos recursos de modo a atender as demandas mais basilares dos cidadãos.

Além disso, a Lei Complementar se mostrou totalmente compatível com os princípios norteadores do sistema constitucional de crises.

Em primeiro plano, a norma cumpre o requisito da Necessidade, haja vista a inequívoca configuração de quadro calamitoso, o qual foi inclusive reconhecido pelo Congresso Nacional por meio do Decreto Legislativo $\mathrm{n}^{\mathrm{O}}$ 6, de 2020, decorrente da pandemia do Covid-19.

O critério da Temporariedade também foi contemplado, uma vez que o caput do art. $8^{\circ}$ prevê que as proibições só perdurarão até 31 de 
dezembro de 2021. A limitação temporal expressa impede que a medida restritiva se prolongue indefinidamente no tempo e, por conseguinte, suprima materialmente o direito.

Igualmente atendida restou a Proporcionalidade, uma vez que a contenção da revisão é medida adequada para conter a expansão das despesas com pessoal; necessária, pois promove a finalidade a que se propõe de modo menos gravoso para os servidores públicos; e proporcional em sentido estrito, na medida em que, para evitar o comprometimento do orçamento, a vedação de revisões se mostra justificável.

Outro elemento de controvérsia reside no inciso I do art. $8^{\circ}$, o qual, ao estabelecer como exceção à regra de vedação a possibilidade de majoração do gasto com pessoal "quando derivado de [...] determinação legal anterior à calamidade pública", permitiria, em tese, a revisão geral anual por se tratar de mandamento constitucional que precede o estado de calamidade.

Tal interpretação não nos parece mais adequada, haja vista que o mero comando contido na Carta Ápice não se mostra suficiente para concretizar a revisão. Conforme apresentado anteriormente, a revisão dos vencimentos demanda a edição de lei específica sobre o tema, bem como a previsão da despesa na Lei de Diretrizes Orçamentárias e na Lei Orçamentária Anual, entendimento este sedimentado pelo Supremo Tribunal Federal com a fixação das teses nos temas 19 e 684 da Repercussão Geral. Nesta linha, para que a revisão geral anual estivesse blindada da regra, os três requisitos deveriam ter sido cumpridos antes da aprovação do Decreto Legislativo 06/2020, o que não ocorreu.

Desta forma, é possível concluir que a Lei Complementar 173 é compatível com a Constituição Federal e a vedação contida no art. $8^{\circ}$, I não se aplica à revisão geral anual. 


\section{CONSIDERAÇÕES FINAIS}

À luz do exposto, verifica-se que a revisão, quando instituída na Constituição Federal de 1988, não teve a sua periodicidade delimitada. O contexto hiperinflacionário nacional contribuiu para que revisões fossem concedidas com o fito de evitar que a desvalorização monetária aviltasse as remunerações dos servidores.

Com a promulgação da Emenda Constitucional 19, de 1998, que estabeleceu a revisão geral anual, parcela significativa da doutrina encampou a tese de que a revisão compreende uma majoração dos vencimentos para, pelo menos, acompanhar os índices inflacionários.

A jurisprudência pátria comungou desse entendimento ao longo dos anos, apontando a inconstitucionalidade da omissão do Poder Executivo ao não enviar a proposta de revisão para o Poder Legislativo. Posteriormente, o entendimento foi alterado para desobrigar o Poder Executivo de enviar a proposta, contudo, condicionou à apresentação de manifestação acerca desta decisão. A Suprema Corte brasileira ainda sedimentou a discussão acerca dos requisitos para concessão da revisão, fixando a necessidade não apenas de lei específica, mas também de previsão na Lei de Diretrizes Orçamentárias e na Lei Orçamentária Anual, na forma do art. $169, \S 1^{\circ}$ da Constituição Federal.

No que se refere aos índices de revisão, o argumento da majoração equiparada aos percentuais inflacionários choca-se diretamente com o inciso XIII do art. 37 da CF/88, o qual veda expressamente a vinculação da remuneração dos servidores públicos. Tal entendimento foi reiterado pelo Supremo Tribunal Federal e subsidiou a edição da Súmula Vinculante 42.

No que tange à calamidade pública, verificou-se que, apesar de a Lei Maior não disciplinar a calamidade pública em seu texto, o ordenamento jurídico pode, de forma infraconstitucional, delimitar regramentos específicos para a situação e medidas excepcionais podem ser adotadas, desde que pautadas na legalidade, em conformidade com a Constituição e 
atendam aos requisitos de necessidade, temporariedade e proporcionalidade, próprios do sistema de crises.

O diagnóstico do quadro atual permite concluir que a vedação à revisão geral anual prevista na Lei Complementar 173 é constitucional, pois reforça a harmonia entre os Poderes e o pacto federativo. Ademais, a análise da evolução jurisprudencial do Supremo Tribunal Federal assenta a eficácia mediata do dispositivo constitucional, de modo que afasta a ideia de concessão automática da revisão. Além disso, encontra-se adequada para o momento de instabilidade, estabelecendo uma medida de excepcionalidade sem violar as garantias fundamentais.

O presente artigo, no entanto, está limitado a uma análise prévia da questão e não apresenta uma conclusão do problema enfrentado, haja vista que as ADIs referentes ao tema ainda estão pendentes de julgamento e o resultado poderá contribuir para o desenvolvimento de novas reflexões e pesquisas sobre o objeto de estudo.

\section{REFERÊNCIAS}

ABRAHAM, M. Curso de direito financeiro brasileiro. 5. ed. Rio de Janeiro: Forense, 2018.

ALEXY, R. Teoria dos direitos fundamentais. Tradução: Virgílio Afonso da Silva. 5. ed. São Paulo: Malheiros, 2008.

ANDRADE, C. O controle do endividamento público e a autonomia dos entes da Federação. 2012. Dissertação (Mestrado em Direito) - Faculdade de Direito da Universidade de São Paulo, São Paulo, 2012.

ARAIS, J. K. Calamidade Financeira e a Lei de Responsabilidade Fiscal: necessidade pública ou liberdade administrativa? Cadernos de Finanças Públicas, Brasília, DF, v. 19, n. 2, p. 1-96, 2019. 
ARAÚJO, L. A. D.; NUNES JÚNIOR, V. S. Curso de direito constitucional. 5. ed. São Paulo: Saraiva, 2001.

ÁVILA, H. B. Teoria dos princípios: da definição à aplicação dos princípios jurídicos. 4. ed. São Paulo: Malheiros Editores, 2005.

BANDEIRA DE MELLO, C. A. Curso de direito administrativo. 32. ed. São Paulo: Malheiros Editores, 2015.

BENEDET, R. Lei nacional e lei federal: a repartição de competências na Constituição da República Federativa do Brasil de 1988. Revista Novos Estudos Jurídicos, Itajaí, v. 11, n. 2, p. 301-312, 2006.

BRASIL. Senado Federal. Subcomissão dos Direitos dos Trabalhadores e Servidores Públicos. Ata de comissões. Brasília, DF: Senado Federal, 1987. Disponível em: https://bit.ly/35AAmLq. Acesso em: 17 maio 2020.

CAMPOS, H. A. Mecanismos de defesa da ordem democrática e do Estado: uma análise comparada do estado de sítio e da constituição de emergência. Revista Direito, Estado e Sociedade, Rio de Janeiro, n. 38, 2011.

CARVALHO FILHO, J. S. Manual de direito administrativo. 28. ed. São Paulo: Atlas, 2015.

CLARK, G; CORRÊA, L. A; NASCIMENTO, S. P. A constituição econômica entre a efetivação e os bloqueios institucionais. Revista da Faculdade de Direito da UFMG, Belo Horizonte, n. 71, p. 675-700, 2018.

CLARK, G; LIMA, M. J. N. A questão do reajuste anual dos servidores públicos em face da omissão legislativa. Revista Brasileira de Filosofia do Direito, Belém, v. 5, n. 2, p. 159-175, 2019. 
COELHO, H. A. Recomposição das perdas inflacionárias da remuneração dos servidores públicos. Revista do TCEMG, Belo Horizonte, v. 85, n. 4, p. 230-241, 2012.

CORAZZA, G. A superinflação brasileira em 1989: notas e comentários. Disponível em: https://bityli.com/197yC. Acesso em: 16 maio 2020.

CRUZ, G. D. M. Calamidade Pública, Estado de Defesa e Estado de Sítio: Características, Distinções e Limites em Tempos de Pandemia. In: BAHIA, S. J. C. (org.). Direitos e deveres fundamentais em tempos de coronavírus. São Paulo: Editora Iasp, 2020.

DI PIETRO, M. S. Z. Direito administrativo. 32. ed. Rio de Janeiro: Forense, 2019.

ELIAS, G. T. Revisão geral e anual da remuneração dos servidores públicos: subsídios hermenêuticos para sua redenção. Revista Controle, Fortaleza, v. 9, n. 2, p. 215-234, 2011.

FERRAZ, L. A. Comentário ao artigo 37, inciso X. In: CANOTILHO, J. J. G.; MENDES, G.F.; SARLET, I. W.; STRECK, L. L. (org.). Comentários à Constituição do Brasil. São Paulo: Saraiva, 2013.

GIRARDI, G. OMS declara pandemia de novo coronavírus; mais de 118 mil casos foram registrados. O Estado de S. Paulo, São Paulo, 11 mar. 2020. Disponível em: https://bit.ly/31NNFxq. Acesso em: 10 maio 2020.

GROTTI, D. A. M. Retribuição dos servidores: análise dos incs. X a XV do art. $37 \mathrm{CF} / 88$, com as modificações introduzidas pela emenda constitucional da Reforma Administrativa. Revista de Direito Constitucional e Internacional, São Paulo, v. 24, p. 51-61, 1998. 
LEITE, H. F. Autoridade da Lei Orçamentária. Porto Alegre: Livraria do Advogado, 2011.

MARIANO, C. M. Revisão geral anual dos vencimentos - comentários ao art. 37, inciso X da CF/88. Revista de Direito Administrativo, Rio de Janeiro, v. 227, p. 151-155, 2002.

PASCOETTO, L. G. L. Triunviratos de emergência. 2012. Tese (Doutorado em Direito do Estado) - Faculdade de Direito da Universidade de São Paulo, São Paulo, 2012.

PINHEIRO, H. F. Calamidade pública. Revista de Direito Administrativo, Rio de Janeiro, v. 36, p. 38-46, 1954. Disponível em: https://bityli. com/Lwbt0. Acesso em: 8 jun. 2020.

SILVA, J. A. Comentário contextual à Constituição. 5. ed. São Paulo: Malheiros, 2008.

SIQUEIRA, C. B.; BUSSINGUER, E. C. A. O mandado de injunção para garantir o direito fundamental à irredutibilidade de vencimento e à revisão anual do servidor público. Scientia Iuris, Londrina, v. 21, n. 3, p. 70-98, 2017. Disponível em: https://bityli.com/fU27v. Acesso em: 28 abr. 2020. 